\title{
As narrativas jornalísticas sobre o sofrimento estudantil e a medicalização da universidade
}

\author{
Journalistic narratives about student suffering and the perspective from \\ medicalization by the university
}

Narrativas periodísticas sobre el sufrimiento de los estudiantes y su
medicalización desde la perspectiva de la universidad

Henrique Mazetti ${ }^{1, a}$

mazetti@gmail.com | https://orcid.org/o000-0001-5498-8294

${ }^{1}$ Universidade Federal de Viçosa, Departamento de Comunicação Social. Viçosa, MG, Brasil.

Doutorado em Comunicação e Cultura pela Universidade Federal do Rio de Janeiro.

\section{RESUMO}

Este artigo investiga como a imprensa brasileira apresenta ao público a questão do sofrimento psíquico e do adoecimento mental de estudantes universitários. Para tanto, foi selecionado um corpus composto por 53 matérias jornalísticas obtidas nos principais veículos online do Brasil sobre o tema da saúde mental na universidade, no período de 2017 a 2019. Os textos foram analisados no sentido de identificar padrões nos modos de narrar o sofrimento estudantil, qual é o perfil dos estudantes que protagonizam as matérias, quem são os profissionais e especialistas autorizados a opinar sobre o tema e a partir de quais dados e saberes as reportagens fundamentam suas informações. O estudo indica que o sofrimento estudantil é codificado a partir da perspectiva da medicalização e poucas são as referências ao contexto socioeconômico e político no qual o mal-estar é gerado.

Palavras-chave: Saúde mental; Medicalização; Universidade; Jornalismo; Sofrimento. 


\section{ABSTRACT}

This article investigates how the Brazilian press covers the problem of psychological distress and mental disorders among university students. To this end, it was selected a corpus composed of 53 journalistic articles published by online media in Brazil on the subject of mental health at the university from 2017 to 2019. The texts were analyzed with the objective of identifying narrative patterns about student suffering, what is the profile of the students who appear in the articles, who are the professionals and experts whose opinions on the topic are considered legitimate and which data and knowledge are used by the articles to support their information. The study indicates that the student suffering is codified, in the analyzed articles, from the perspective of medicalization and there are few references to the socioeconomic and political context in which the malaise is caused.

Keywords: Mental health; Medicalization; University; Journalism; Suffering.

\section{RESUMEN}

Este artículo investiga cómo la prensa brasileña cubre el problema de lo sufrimiento psicológico y los trastornos mentales de los estudiantes universitarios. Con este fin, se seleccionó un corpus compuesto por 53 artículos periodísticos publicados por los medios online en Brasil sobre el tema de la salud mental en la universidad desde 2017 hasta 2019. Los textos fueron analizados con el objetivo de identificar patrones narrativos acerca del sufrimiento de los estudiantes, cual es el perfil de los estudiantes que se manifiestan en los artículos, cuales son los profesionales y expertos cuyas opiniones sobre el tema se consideran legítimas y qué datos y conocimientos utilizan los artículos para respaldar sus informaciones. El estudio indica que el sufrimiento del estudiante está codificado, en los artículos analizados, desde la perspectiva de la medicalización y hay pocas referencias al contexto socioeconómico en el que se produce el malestar.

Palabras clave: Salud mental; Medicalización; Universidad; Periodismo; Sufrimiento.

Contribuição dos autores: o autor é responsável por todo o texto.

Declaração de conflito de interesses: não há.

Fontes de financiamento: bolsa de Pós-Doutorado Júnior do Conselho Nacional de Desenvolvimento Científico e Tecnológico (CNPq).

Considerações éticas: não há.

Agradecimentos/Contribuições adicionais: não há.

Histórico do artigo: submetido: 26 abr. 2020 | aceito: 26 maio 2020 | publicado: 30 set. 2020.

Apresentação anterior: não houve.

Licença CC BY-NC atribuição não comercial. Com essa licença é permitido acessar, baixar (download), copiar, imprimir, compartilhar, reutilizar e distribuir os artigos, desde que para uso não comercial e com a citação da fonte, conferindo os devidos créditos de autoria e menção à Reciis. Nesses casos, nenhuma permissão é necessária por parte dos autores ou dos editores. 


\section{INTRODUÇÃO}

Em 2019ํㅜ a Associação Nacional dos Dirigentes das Instituições Federais de Ensino Superior (Andifes) divulgou a quinta edição de sua pesquisa nacional sobre o perfil socioeconômico e cultural de estudantes do ensino superior em instituições federais. O levantamento revelou que 83,5\% dos entrevistados declararam ter tido algum tipo de dificuldade emocional durante seus estudos. A primeira edição da pesquisa, feita em $1996^{2}$, não abordava a questão. Desde então, porém, os números apontam um aumento significativo dos problemas de saúde mental entre os universitários. Na segunda edição do levantamento, realizada em $2003^{3}, 36,9 \%$ dos estudantes afirmaram ter tido problemas emocionais na universidade. Em 2010 quando se deu a terceira edição da pesquisa, o percentual saltou para 47,7\%. E em 20145 , na quarta edição do levantamento, o número de universitários com dificuldades emocionais já alcançava 79,8\%.

Ainda que a questão não seja, portanto, especialmente nova, discussões sobre a saúde mental na universidade ganharam intensa visibilidade nos últimos anos. Estudantes se movimentam nos sites de redes sociais para divulgar campanhas que reivindicam cuidados, denunciam abusos e relatam situações que geram mal-estar no ambiente universitário ${ }^{6}$. As instituições de ensino superior organizam, por sua vez, eventos para debater a questão, promovem atividades preventivas e buscam ampliar seus quadros de assistência psicossocial. A imprensa se configura, também, como um espaço de difusão dos discursos sobre saúde mental na universidade, ao oferecer enquadramentos interpretativos para o tema por meio de reportagens que reproduzem testemunhos de estudantes, divulgam iniciativas de instituições de ensino e difundem opiniões de especialistas sobre o fenômeno.

Este artigo investiga como a imprensa brasileira apresenta ao público a questão do sofrimento psíquico e do adoecimento mental de estudantes universitários. Informado por uma perspectiva foucaultiana sobre o discurso e o saber ${ }^{7,8}$, o trabalho problematiza quais são as condições nas quais as discussões sobre saúde mental na universidade ganham destaque e legitimidade. Isso significa compreender que a emergência desses debates não é natural e inevitável, mas historicamente condicionada por movimentos de ruptura e continuidade nas formas de se pensar a universidade, o mal-estar e a doença mental. A irrupção de discursos sobre sofrimento estudantil nas instituições de ensino superior é um acontecimento em si mesmo capaz de moldar condutas pessoais e institucionais e de estabelecer limites para os modos como os indivíduos têm experiências de si e do outro.

A análise do aspecto discursivo do fenômeno é realizada a partir de um quadro teórico que aborda as dimensões políticas e culturais do mal-estar9-11. Se o sofrimento possui, inegavelmente, uma determinação biológica, as maneiras como as pessoas interpretam, justificam e se posicionam em relação ao seu próprio sofrimento e ao do outro são também determinadas culturalmente. O mal-estar não é apenas uma sensação individual e subjetiva, mas também um fenômeno social, organizado por uma gramática moral que define quem pode sofrer, quais são os modos legítimos de expressar o sofrimento, para quais atores deve ser distribuída a responsabilidade pelo mal-estar e como ele pode ser apaziguado. Isso não quer dizer que o sofrimento não seja 'verdadeiro', mas que os indivíduos se relacionam com seu sofrimento de maneiras contingentes e contextualizadas.

Espera-se que o artigo contribua para os debates sobre saúde mental na universidade ao tornar visíveis naturalizações nos modos de dar sentido ao sofrimento estudantil, que conferem caráter autoevidente e inquestionável a certas interpretações do fenômeno, enquanto excluem outras possibilidades de codificação do mal-estar. É importante frisar que o artigo não tem nenhuma intenção normativa ou profilática. Não está em discussão, aqui, a 'verdade' sobre os relatos de sofrimento estudantis ou a parcela de culpa da universidade na gestão da dor psíquica de seus estudantes. O que motiva o artigo é a intenção de explicitar as singularidades que marcam as atuais formas de dar sentido ao sofrimento na universidade e como elas se articulam (ou ocultam as articulações) com dinâmicas mais amplas da sociedade contemporânea. 


\section{METODOLOGIA}

Para investigar como a imprensa brasileira tem abordado a questão da saúde mental dos estudantes universitários foi realizado um extenso levamento nos principais veículos jornalísticos online do país. A partir de pesquisas refinadas nos sistemas do Google, Google News e nos próprios mecanismos de buscas dos veículos consultados, foram coletadas 53 matérias, publicadas no período de 2017 a 2019, em revistas e jornais diários de enfoque nacional ou estadual. A escolha por restringir o levantamento ao ambiente digital foi orientada por fatores de viabilidade e praticidade. Já o recorte temporal foi estabelecido durante uma etapa inicial de pesquisa, quando se verificou que, nos anos anteriores, o número de matérias sobre o tema era extremamente escasso. Das 53 matérias que compõem o corpus do trabalho, 18 são de 2017, 24 de 2018 e 11 de 2019. Esses números não contemplam matérias que foram descartadas por não terem como foco específico a questão do sofrimento psíquico e do adoecimento mental dos estudantes universitários ou porque apresentaram apenas dados factuais para divulgação de ações preventivas nas universidades. Foram selecionadas, portanto, apenas reportagens de maior fôlego, que apresentam múltiplas fontes de informação, além de artigos de opinião.

A pesquisa tem caráter qualitativo, exploratório e interpretativo. Após serem reunidas, as matérias foram analisadas no intuito de identificar padrões nos modos de narrar o sofrimento estudantil, qual é o perfil dos estudantes que protagonizam as matérias, quem são os profissionais e especialistas autorizados a opinar sobre o tema e a partir de quais dados e saberes as reportagens fundamentam suas informações. Os resultados da análise e as discussões teóricas que a orientam são apresentados em três seções. Na primeira parte, discute-se em termos teóricos os modos como o sofrimento possui especial importância nas formas de subjetivação contemporâneas. Na segunda seção, é feita uma descrição aprofundada da estrutura típica observada nas matérias selecionadas. A partir de um exemplo representativo do corpus encontrado em uma reportagem publicada no jornal O Estado de S. Paulo em 2017, são abordados os principais elementos e atores convocados na construção narrativa jornalística sobre o sofrimento estudantil na universidade. Na terceira seção, destacamos a ênfase dada ao saber médico que ampara as matérias analisadas, e apresentamos algumas reportagens que fogem a essa regra e, assim, demonstram as possibilidades de conferir outros sentidos ao sofrimento estudantil. Observamos, também, como os textos selecionados tendem a descrever a universidade como uma realidade fechada em si mesma, distante de dinâmicas que perpassam a sociedade, e discutimos como essa estratégia silencia certas formas de indignação política relacionadas ao sofrimento estudantil.

\section{SOFRIMENTO E SUBJETIVAÇÃO}

A experiência do sofrimento é, na contemporaneidade, uma forma privilegiada de produção de verdade sobre si. Dunker" sugere que "pensar nossa individualização a partir da forma como estruturamos o sofrimento na linguagem é um capítulo decisivo de nossa política de subjetivação. A maneira como interpretamos ou codificamos, nomeamos ou metaforizamos, descrevemos ou narramos nossa experiência de sofrimento transforma sua natureza, extensão e intensidade". Para o autor, o sofrimento não escapa às dinâmicas de poder, que envolvem a produção de narrativas e atos de reconhecimento. Por um lado, concorrem narrativas que estabelecem valor e legitimidade a diferentes modos de sofrer. Nessa disputa, a própria externalização do sofrimento é colocada em questão: tornar o sofrimento público seria uma fraqueza moral para alguns. Por outro lado, e de acordo com um diferente registro moral, expressar o sofrimento seria um direito e ter o sofrimento reconhecido seria capaz de mobilizar uma "luta feroz"9 (p. 13), na medida em que o reconhecimento da dor pessoal ou de um grupo passa a ser compreendido como mecanismo fundamental para a sustentação de um modo de fazer política. 
Para Illouz ${ }^{12}$, a importância do sofrimento nos modos de construção identitária contemporâneos estaria ligada à emergência de um "capitalismo emocional", em que práticas econômicas se difundiriam e se justificariam a partir de um trabalho sobre as emoções individuais. De acordo com a autora, o sofrimento é central nos modos de expressão de si da atualidade, pois as identidades contemporâneas são construídas a partir de premissas oriundas das narrativas de autoajuda, popularizadas pela mídia e legitimadas pelas autoridades 'psi'. Nessas narrativas, predominam os imperativos de responsabilidade individual e autodeterminação para a superação dos mais variados problemas da vida cotidiana. Ainda que as narrativas de autoajuda se orientem por premissas de felicidade, saúde e autorrealização, elas possuem como umas de suas estratégias centrais a identificação de sofrimentos e as deficiências pessoais que impedem a conquista do bem-estar. Assim, Illouz ${ }^{12}$ sugere que as narrativas de autoajuda estimulam uma compreensão da vida como uma "disfunção generalizada", em que a identificação e a exposição de sofrimentos se transformam em uma condição fundamental para a sua superação, via de regra a partir da força de vontade individual e em nome do autodesenvolvimento pessoal.

A noção de trauma tem importante papel na articulação entre sofrimento e experiências de si. Para Illouz ${ }^{12}$, a rememoração de um acontecimento traumático em um passado longínquo (em geral, na infância) possibilita que o indivíduo seja liberado da responsabilidade pelo seu próprio sofrimento, ainda que ele continue sendo responsável por se livrar do mal-estar psíquico. O sofredor é convidado, dessa forma, a pensar sobre si como uma espécie de herói, capaz de superar as mais diferentes adversidades enquanto impulsionado exclusivamente pelo seu esforço individual. Uma narrativa, portanto, em perfeita conformidade com os ideais neoliberais de meritocracia e empreendimento de si. O sofrimento e adoecimento, nesse contexto, são distanciados de qualquer relação com as hierarquias e formas de organização social. Como argumenta $\mathrm{Han}^{13}$, "quem fracassa na sociedade liberal do desempenho, em vez de questionar a sociedade ou o sistema, considera a si mesmo como responsável e se envergonha por isso". Han observa que a prevalência da codificação do sofrimento em doenças psíquicas como depressão e síndrome de burnout indica uma autoexploração do indivíduo sobre si mesmo. O capitalismo emocional descrito por Illouz ${ }^{12}$ é chamado por $\operatorname{Han}^{13}$ de psicopolítica, uma técnica de poder baseada na gestão das emoções.

É a partir de uma compreensão política do sofrimento que, agora, faremos uma análise das narrativas jornalísticas sobre o mal-estar estudantil nas universidades. Ao longo das próximas seções, apresentaremos ainda discussões teóricas que se articulam à perspectiva sobre o sofrimento aqui esboçada, aprofundando as discussões a partir de reflexões sobre as diferenças históricas nas formas de narrar o sofrimento, bem como os processos de medicalização de dilemas cotidianos que marcam a sociedade contemporânea.

\section{FORMAS DE NARRAR O SOFRIMENTO ESTUDANTIL}

Em 16 de setembro de 2017, o jornal O Estado de S. Paulo publicou uma extensa reportagem em seu site, composta por quatro matérias publicadas em páginas diferentes, mas conectadas por meio de hiperlinks. A primeira matéria recebeu o título "Aumento de transtornos mentais entre jovens preocupa universidades" ${ }^{14}$. Abriam o texto dois relatos de estudantes universitários que haviam passado por situações de adoecimento mental durante a graduação, que acarretaram a internação numa instituição psiquiátrica de um dos universitários e uma tentativa de suicídio de outra aluna. Na sequência, o texto apresentava estatísticas sobre casos de tentativas de suicídio em universidades federais paulistas, comentadas por um psicólogo do Departamento de Atenção à Saúde (DAS) de uma das universidades citadas. A matéria ainda possuía mais duas seções, separadas por intertítulos. Em uma delas, foram listadas diferentes iniciativas de universidades federais do país para lidar com o adoecimento mental dos seus estudantes. Na outra, foram descritas mobilizações estudantis nos sites de redes sociais que reivindicavam assistência e promoviam ações de apoio terapêutico aos estudantes. 
A segunda matéria, intitulada "Eu deixei de ter prazer em ir às aulas', diz aluna de Medicina" ${ }^{15}$, foi composta exclusivamente pelo testemunho, em primeira pessoa, de uma estudante de medicina que desenvolveu um histórico de automutilações e depressão durante a faculdade. A terceira matéria, "Nas federais, 3 estudantes em cada 10 já procuraram psicólogo"16, consistiu em apresentar estatísticas obtidas pela Pesquisa Nacional de Perfil Socioeconômico e Cultural de Estudantes de Institutos Federais de Ensino Superior, realizada em 2016 pela Associação Nacional dos Dirigentes das Instituições Federais de Ensino Superior (Andifes) e também por um estudo da Faculdade de Ciências Médicas da Universidade Estadual de Campinas (Unicamp) com estudantes que receberam apoio psicológico e psiquiátrico da instituição. A última matéria, "Alunos relatam encontrar dificuldade para obter auxílio psicológico"17, apresenta testemunhos de desamparo e falta de acolhimento dos estudantes com problemas de saúde mental nas universidades. As falas dos alunos foram contrapostas a entrevistas com professores e dirigentes universitários, que enumeraram ações das instituições de ensino para atender aos estudantes que necessitavam de apoio psicológico. O texto da última matéria se encerra com dicas para o leitor observar os sinais mais comuns dados pelos jovens universitários quando desenvolvem transtornos psiquiátricos.

A separação da reportagem em quatro matérias menores permite explicitar os tipos de atores que são convocados pela imprensa para tratar a questão e qual o papel atribuído a cada um deles no material analisado. A reportagem do Estado de S. Paulo exemplifica ainda um padrão narrativo encontrado nas matérias observadas. Os textos coletados começam com relatos de mal-estar de estudantes, contextualizados na sequência por estatísticas que fornecem uma dimensão quantificada do problema, ou então, inversamente, começam com estatísticas que apontam a prevalência de questões relativas à saúde mental entre os estudantes e são, posteriormente, ilustradas com depoimentos de universitários. Em seguida, são convocados os especialistas, chamados a interpretar a situação, explicar suas causas e estabelecer quais seriam as formas ideias de prevenção e tratamento. Há um predomínio significativo de psicólogos e psiquiatras como fontes, basicamente os únicos profissionais ouvidos nas matérias. Finalmente, são descritas as ações tomadas pelas instituições de ensino para lidar com o fenômeno e são apresentados os posicionamentos das universidades sobre a questão, por meio de entrevistas com coordenadores pedagógicos ou responsáveis pela direção de centros de apoio psicossocial voltados para o atendimento dos estudantes. Algumas matérias ainda oferecem gráficos e informações sobre serviços de atendimento médico e terapêutico ao público. Outras usam a infografia para ilustrar com detalhes os resultados de pesquisas citadas ao longo dos textos. As imagens usadas nas matérias são, em geral, meramente evocativas: fotos de arquivo de atividades rotineiras da universidade e de estudantes reunidos ou, então, fotografias que dramatizam o mal-estar e a solidão dos estudantes, por meio de poses e jogos de luz e sombras.

Essa estrutura privilegia a construção de uma narrativa em que estudantes e instituições de ensino são apresentados como agentes de um confronto, em que os especialistas assumem o papel meramente técnico e isento de avaliar a situação, o de identificar suas causas, comentar sobre a eficácia de ações já tomadas e propor soluções alternativas. O ideal de fornecer vários pontos de vista sobre um mesmo tema ou acontecimento é um tópico constantemente abordado em textos sobre técnicas de reportagem e ética jornalística ${ }^{18,19}$. Ao analisar manuais de redação de grandes jornais brasileiros, Ramos e Souza ${ }^{20}$ observam, porém, que a preocupação em cobrir uma pluralidade de fontes de informação é, frequentemente, reduzida à famosa máxima de "sempre ouvir o outro lado", especialmente em casos controversos e quando há acusações que exigem direito de resposta. De acordo com as observações das autoras, as matérias analisadas tendem a codificar o sofrimento psíquico e o adoecimento mental dos estudantes a partir de uma dinâmica entre acusações e defesas. As fontes consultadas e o modo como as informações são apresentadas ao leitor não operam no sentido de fornecer várias possibilidades interpretativas para o fenômeno. Pelo contrário, a questão é simplificada e resumida à estrutura de uma denúncia, em que a parte acusada tem amplo espaço de defesa. Nas matérias analisadas, são raríssimos os casos em que estudantes, professores e demais 
representantes das instituições de ensino são descritos como integrantes de uma comunidade acadêmica com problemas e objetivos comuns.

Em parte, a constância desse padrão narrativo está relacionada aos fatores que levaram os jornais a pautarem a questão. Foi possível identificar quatro tipos de motivação principais para a realização das matérias: casos específicos de suicídio de estudantes, divulgação de dados de pesquisa sobre a saúde mental dos alunos, lançamento de ações das instituições de ensino para prevenção e atendimento psicológico aos universitários, e cobertura de manifestações estudantis sobre o tema nos sites de redes sociais. Em todos as situações, foi feita a escolha de conferir funções específicas às fontes ouvidas, em outro padrão que se repete em quase todos os textos analisados. Aos estudantes, coube relatar seu sofrimento, enquanto os dirigentes universitários receberam o direito de defender as universidades. Estatísticas resultantes de pesquisas científicas foram usados para comprovar a gravidade do problema e especialistas ouvidos ficaram responsáveis por apresentar as causas e os métodos de prevenção. A persistência de uma mesma estrutura narrativa e dos papéis dados aos atores identificados nas matérias é sinal de que há um certo consenso sobre as estratégias consideradas adequadas para abordar o tema, condizente com o modo como se desenvolvem narrativas midiáticas sobre outras formas de sofrimento na contemporaneidade. Essa relação com os modos de narrar o sofrimento predominantes atualmente fica mais explícita ao observarmos certas caraterísticas dos depoimentos dos alunos entrevistados e da distribuição de responsabilidades pelo adoecimento estudantil implícita nos textos selecionados.

O perfil dos estudantes que testemunham suas experiências de mal-estar na universidade nas matérias analisadas é muito diverso. Cursos de maior prestígio, como medicina e engenharia aparecem com mais frequência, mas estudantes dos mais variados cursos protagonizam relatos de sofrimentos. A mesma situação ocorre em relação às instituições de ensino que as fontes entrevistadas frequentam. Universidades públicas dos grandes centros (Universidade de São Paulo - USP, Universidade Federal de Minas Gerais - UFMG, Universidade Estadual de Campinas - Unicamp e Universidade de Brasília - UnB) são mais citadas, mas faculdades públicas e privadas, sediadas em cidades de menor e maior porte, recebem menções. Na grande maioria dos casos, os estudantes ouvidos são descritos apenas por meio do seu nome (ou então, um nome fictício), idade, curso e instituição em que estuda. Em algumas matérias, o relato permite a identificação de outros dados dos estudantes ouvidos, como situação econômica e familiar, orientação sexual, raça e localidade de origem. Mas o principal destaque dado nas falas dos estudantes é para o próprio processo de sofrimento, procura por um diagnóstico, tratamento e, em alguns casos, superação do transtorno.

A necessidade de agir diante da expressão pública do sofrimento de estranhos foi generalizada na modernidade a partir de uma política da piedade, que transformava em regra moral a solidariedade dos não sofredores por aqueles que sofrem algum tipo de infortúnio à distância ${ }^{21}$. Antes da modernidade, o encontro com o sofrimento de um estranho não carregava a exigência moral de solidariedade, pois ela se organizava por laços comunitários e não implicava, necessariamente, uma dimensão política, mas a compaixão por aqueles que estavam próximos. Vaz e Rony ${ }^{22}$ observam, contudo, que a política da piedade tem se enfraquecido. Ao longo do século XX, fortaleceram-se novos preceitos morais que alteram o modo como as sociedades ocidentais dão sentido à exposição do sofrimento. Essa transformação histórica muda também os modos como os sofrimentos são narrados, o que envolve uma outra maneira de distribuir a responsabilidade pelo sofrimento e, portanto, a promoção de outros tipos de ação política para suprimi-lo. A expansão do que pode ser denominado de sofrimento e a generalização da condição subjetiva de vítima são duas rupturas apontadas pelos autores como condições para que uma "política da vítima" ${ }^{22}$ substitua, na contemporaneidade, a política da piedade, tipicamente moderna.

Os modos de narrar o sofrimento orientados pela política da piedade eram motivados por preocupações de ordem coletiva, segundo os autores. Uma vez que as narrativas sobre o sofrimento se preocupavam com o infortúnio de grandes grupos de pessoas, elas despersonalizavam a figura do sofredor. Inclinações 
e acontecimentos pessoais só eram de interesse público à medida que eles fossem partilhados por muitos, conferindo caraterísticas exemplares ao sofredor. Além disso, nas formas de narrar o sofrimento organizadas pela política da piedade, "a audiência é endereçada como os felizes que devem agir politicamente para reduzir os sofrimentos dos infelizes. Se deve agir, a audiência também é endereçada como responsável”22. Portanto, não só o sofrimento era coletivo, mas também a responsabilidade por sua redução. Assim, o sofrimento adquiria dimensões políticas, na medida em que se ligava a questões sociais que exigiam transformações na sociedade.

$\mathrm{Na}$ contemporaneidade, contudo, surgem novas maneiras de narrar o sofrimento que deslocam a orientação coletiva da política da piedade para uma direção mais individual. A ascensão da figura da vítima é acompanhada do aumento da importância dada ao reconhecimento do seu sofrimento pessoal. Assim, a figura do sofredor não é mais despersonalizada, mas cada vez mais baseada em sujeitos concretos. Vaz e Rony ${ }^{22}$ observam que os relatos de sofrimento contemporâneos abordam detalhes do passado e da personalidade da vítima, que não ganhavam destaque nas narrativas de sofrimento modernas. Outra característica das narrativas contemporâneas é a crise da representação dos sofredores e a tendência de que a própria vítima testemunhe seu sofrimento. A escolha do jornal O Estado de S. Paulo de dedicar uma das quatro matérias da série apenas à transcrição do depoimento em primeira pessoa de uma das estudantes ilustra como as reportagens sobre saúde mental na universidade se aproximam das narrativas baseadas na política da vítima.

O relato da estudante, identificada pelo seu nome, idade, curso e instituição que frequenta, narra um percurso pessoal e específico, que não tem como objetivo exemplificar o sofrimento de um grupo maior de pessoas, mas o de reconhecer o sofrimento da vítima e confirmar a sua inocência diante do sofrimento. A estudante narra, assim, como "nunca tinha tido sintomas de depressão" 15 antes de entrar na faculdade, e como sempre foi "uma aluna dedicada'15". O passado da estudante é, então, acompanhado pela narração de sua trajetória de adoecimento e busca por tratamento. A ênfase na inocência do sofredor é um aspecto chave das narrativas de sofrimento contemporâneas, pois elas realizam uma redistribuição de responsabilidades, quando comparadas aos modos modernos de narrar o sofrimento. Na modernidade, o sofrimento ainda poderia ser atribuído ao acaso ou poderia ser concebido como inevitável. Vaz e Rony ${ }^{22}$ sustentam que nas formas atuais de narrar o sofrimento, entretanto, o infortúnio não é retratado como eventualmente imprevisível, mas, pelo contrário, como aquilo que poderia ser evitado e só não o foi por omissão ou incompetência dos responsáveis.

Nas narrativas midiáticas analisadas por Vaz e Rony ${ }^{22}$, o Estado era o grande responsável pela negligência que gerava o sofrimento alheio. Nas matérias sobre saúde mental na universidade, é a própria universidade ou os seus agentes que são responsáveis pelo sofrimento narrado, uma vez que não agem para minimizar ou contribuem ativamente para o sofrimento das vítimas. Na reportagem do Estado de S. Paulo ${ }^{23}$, assim como em várias outras matérias analisadas, a questão é apresentada como resultado de uma falha moral ou traço de personalidade individual de um grupo de professores que não possuiriam "empatia" ou "sensibilidade": "De acordo com universitários ouvidos pelo [jornal] Estado, alguns professores e diretores de unidades são insensíveis ou inflexíveis, outros desqualificam e minimizam os quadros do tipo"14. Um grupo de matérias localiza na figura dos orientadores uns dos principais vilões da saúde mental na universidade. Uma reportagem da Folha de S.Paulo, que reúne testemunhos recebidos pelo jornal após a publicação de uma matéria sobre o suicídio de um estudante de pós-graduação da USP, afirma: "Na intersecção da maioria das dificuldades descritas pelos estudantes - pressão exagerada, carga de trabalho frequentemente excessiva, solidão, assédio moral, entre outras encontra-se a figura do orientador, o professor responsável por ajudá-los a realizar a tese e prepará-los para a pesquisa acadêmica. [...] Não raro, como atestam os relatos, orientadores se mostram despreparados para lidar com os alunos e exercer o papel esperado na formação deles”23. 
Os relatos dos estudantes narram, algumas vezes, situações extremas de abusos verbais, morais e até mesmo sexuais envolvendo professores e outros estudantes universitários. Entretanto, as matérias raramente desenvolvem a sua apuração em torno das denúncias de abuso. O foco se restringe à descrição do sofrimento da vítima e à denúncia pública da agressão. Essa escolha narrativa tem importantes consequências políticas. Uma vez que a política da piedade organizava uma narrativa em que todos estavam implicados no sofrimento alheio, a responsabilidade era coletiva, o que demandava uma ação por parte de toda a sociedade em prol do grupo de pessoas que sofria. Nas narrativas baseadas na política da vítima, como é o caso das matérias que abordam a questão da saúde mental na universidade, a responsabilidade não é coletiva, mas direcionada vagamente à instituição universitária ou diretamente relacionada a falhas morais individuais de certos atores universitários. Reduz-se, desta maneira, as possibilidades de ação coletiva, assim como se enfraquece a necessidade de agir a favor de um grupo de pessoas. De acordo com a narrativa construída pelas matérias analisadas, ao aluno, cabe tratamento médico individual, à universidade e aos seus atores, caberia a punição, se não houvesse ampla impunidade.

Nota-se, contudo, nos textos observados, um esforço para demonstrar que as universidades têm tomado atitudes em relação à questão do sofrimento psíquico dos estudantes. Além de quase todas as matérias apresentarem declarações de dirigentes universitários que manifestam como as universidades desenvolvem ações para o acolhimento psicossocial dos estudantes, algumas reportagens são voltadas exclusivamente para a divulgação de iniciativas realizadas pelas instituições de ensino. Ainda que às universidades seja atribuído o papel do 'outro lado' das denúncias nas construções jornalísticas sobre sofrimento psíquico e adoecimento mental dos estudantes, elas recebem amplo espaço de defesa. Entretanto, quando são listadas as atividades realizadas pelas instituições de ensino, outro dado se sobressai. Elas se resumem ao atendimento psicológico dos alunos. O que reforça um elemento central nas narrativas sobre sofrimento estudantil, a medicalização do mal-estar. Neste sentido, se as universidades são apresentadas como responsáveis, seu 'direito de defesa' é garantido não só pela dinâmica do discurso jornalístico, mas também porque o grande inimigo é, na verdade, o próprio mal-estar, que é codificado nas matérias quase exclusivamente como uma doença (ou um conjunto de transtornos), que só pode ser pensada pelos especialistas do saber médico.

\section{A MEDICALIZAÇÃO DA UNIVERSIDADE}

Outro elemento constantenas narrativas sobre sofrimento estudantilésua fundamentação quase exclusiva no saber médico e a invariável aparição de psicólogos e psiquiatras como especialistas responsáveis por contextualizar as informações apresentadas nas matérias analisadas. O enquadramento médico da questão não se resume aos profissionais consultados. O próprio vocabulário das matérias acentua e naturaliza a utilização da perspectiva médica para a compreensão do tema. O sofrimento estudantil é imediatamente definido como um problema de saúde: um sintoma patológico ou uma doença em si mesma. As soluções sugeridas envolvem, necessariamente, tratamentos e formas de prevenção médicos. São constantes as falas que garantem sua importância e eficácia. A busca por 'ajuda profissional' é listada como uma ação primordial, além de ser usada como medida para dimensionar o tamanho do problema, como sustenta o título da matéria do Estado de S. Paulo, "Nas federais, 3 estudantes em cada 10 já procuraram psicólogo"16.

Algumas reportagens assumem um tom que transmite a ideia de um surto ou uma epidemia de mal-estar entre os estudantes e sugerem uma amplitude quase infinita para o fenômeno, como numa manchete do Jornal de Brasília "Maioria dos estudantes da UnB apresenta sintomas de problemas como a depressão"24. Outros textos aproximam a condição de estudante universitário a um fator de risco para adoecimento mental, como em uma matéria da Folha de S.Paulo: "Um estudo publicado neste ano na Bélgica com quase 3.700 estudantes de doutorado mostrou que um terço deles estava sob alto risco de desenvolver uma patologia como a depressão. A taxa, 
segundo a pesquisa, é mais do que o dobro da apresentada por grupos de comparação fora da universidade”25. Esses exemplos demonstram o processo de medicalização da questão do sofrimento psíquico na universidade.

Conrad $^{26}$ define a medicalização como o processo em que um problema, antes interpretado fora do escopo do saber médico, passa a ser "definido em termos médicos, descrito em linguagem médica, compreendido por meio da adoção de uma estrutura médica, ou 'tratado' via intervenção médica" ${ }^{26}$. O autor salienta, amparado em Foucault, que a crítica ao fenômeno da medicalização não envolve problematizar se uma questão é, de fato, de ordem médica, mas questionar como o desenvolvimento e a aplicação de categorias médicas produzem e modificam tanto as práticas de diferentes instituições, quanto os modos como as pessoas pensam e agem sobre si mesmas. A discussão sobre medicalização aponta, portanto, como observa Metzl ${ }^{27}$, para os modos como certas categorias médicas e ideais de saúde estão intimamente ligados a julgamentos de valor e hierarquias morais. Dois movimentos paralelos contribuem para a medicalização generalizada da sociedade. Por um lado, expande-se, cada vez mais, o que pode ser considerado um transtorno. Por outro, a definição do que é saudável se atrofia. Assim, há uma mudança no estatuto da doença, principalmente da doença mental, na contemporaneidade. Se, na modernidade, a doença mental se desenhava na separação entre o normal e anormal, operando como uma forma de exclusão de uma minoria desviante, atualmente a doença tem se desvinculado do comportamento desviante para se associar aos cambiantes ideais de bemestar. Conceber-se como doente na cultura contemporânea, portanto, transforma-se em uma condição para a busca de uma vida longa e prazerosa ${ }^{28}$.

As matérias analisadas colaboram, por um lado, com a ideia de ampliação da noção de doença mental. São diversas as reportagens que apresentam estatísticas que pretendem demonstrar a prevalência dos problemas de saúde mental nos estudantes universitários. Contudo, nota-se a presença de um discurso ainda orientado para retirar o estigma social da doença. "O preconceito de falar sobre doença mental faz com que a gente não fale sobre saúde mental", afirma uma psiquiatra entrevistada em uma reportagem do $\mathrm{G}^{29}$, em um posicionamento que se repete em falas de outros entrevistados. Assim, a separação entre normal e anormal ainda está em funcionamento nesses discursos. No entanto, o comportamento desviante a ser excluído se altera: não é mais um comportamento do doente que precisa ser extinto, mas o comportamento do indivíduo que não reconhece a doença daquele que sofre. Um ponto que se destaca nas falas dos entrevistados, especialmente dos estudantes, é a constante tentativa de descrever o sofrimento ou a incapacidade de reconhecer o sofrimento como algo anormal. Portanto, nas reportagens observadas, a doença não é investida de positividade, nem é vista como livre de preconceitos. Mas o comportamento desviante que merece censura já não é aquele vinculado à doença, e sim aquele que nega a existência da doença ou do sofrimento. Pode-se argumentar que certas falas das reportagens, ao transformarem o sofrimento em anormal, não só aderem à lógica contemporânea de pensar em todo tipo de mal-estar como evitável, mas também defendem a medicalização como única forma de acessar uma vida feliz.

Cabe ressaltar que as reflexões sobre medicalização do ambiente escolar não são novas. Há um debate consolidado no Brasil e no mundo sobre a medicalização da infância, por meio de críticas às formas como diagnósticos de transtorno de déficit de atenção e medicamentos como ritalina, por exemplo, são usados (e potencialmente abusados) para justificar e gerir políticas de educação infantil ${ }^{30,31}$. No caso das universidades, porém, um elemento que diferencia o fenômeno é a atuação dos próprios estudantes universitários no sentido de exigir cuidados com a saúde mental. Se a discussão da medicalização da escola envolve a despatologização de certos comportamentos infantis que facilitariam o 'fracasso escolar', o debate sobre a medicalização da universidade talvez aponte para uma necessária desnaturalização do conceito de saúde mental.

Um número bem menos expressivo de matérias observadas não empregou, contudo, a narrativa da medicalização para abordar o tema do sofrimento dos estudantes universitários. Analisar o modo como essas matérias apresentam a questão talvez demonstre outras formas disponíveis para pensar o mal-estar 
na universidade. Fora do escopo do saber médico, o sofrimento estudantil ganha outras explicações causais, mais atreladas a fatores socioculturais e econômicos, que não são exclusivos da universidade, mas marcam toda a sociedade brasileira.

Uma causa para o sofrimento estudantil menos citada no material analisado, mas que ganha destaque especial em algumas matérias é a situação de vulnerabilidade econômica e simbólica de estudantes cotistas. Para a reportagem do site da revista CartaCapital ${ }^{32}$, o sofrimento estudantil nas universidades é mais uma consequência do racismo estrutural que perpassa as relações sociais brasileiras. "Instabilidade econômica e sensação de despertencimento" 32 são alguns dos males que atingiriam os estudantes universitários, mas eles não são descritos como simples produtos de uma realidade exclusiva às instituições de ensino, e, sim, resultado de vetores de produção de desigualdades fortemente arraigados no país. A matéria mencionada obedece, inicialmente, ao modelo mais típico de reportagem sobre o sofrimento psíquico na universidade: começa com o relato de mal-estar de uma estudante de medicina da USP, contextualiza o testemunho com estatísticas sobre evasão e apresenta outros casos de estudantes. Porém, a palavra do especialista não é dada ao psicólogo ou a um coordenador pedagógico, mas ao diretor de ações afirmativas da Universidade Federal de Juiz de Fora (UFJF), que destaca as dificuldades que muitos estudantes enfrentam antes mesmo de entrarem para a universidade. $\mathrm{O}$ entrevistado sugere atividades de acolhimento que envolvem ações coletivas, em vez de tratamento individual: "Esse esforço maior realizado pelo cotista ao ingressar na universidade pode gerar problemas de saúde mental e dificuldades no relacionamento com os novos colegas. Não é raro que estudantes negros fiquem isolados e não participem das discussões em salas de aula, como os demais estudantes”32. A matéria descreve atitudes preconceituosas de professores e estudantes que produzem sofrimento, mas a universidade não é posicionada como o 'outro lado' da história. Não há falas de representantes das instituições de ensino as defendendo. A reportagem termina com relatos dos estudantes valorizando as experiências possibilitadas pela sua presença na universidade e o contato e a mobilização política com outros estudantes negros.

Matérias como essa são raras no conjunto de reportagens selecionadas, pois em momento nenhum do texto, as causas do mal-estar são atribuídas exclusivamente à universidade, às suas dinâmicas ou aos seus atores. Trabalha-se com a premissa de que a universidade é apenas uma extensão da sociedade, um outro espaço no qual o racismo e as desigualdades econômicas estruturais geram processos de exclusão e situações de vulnerabilidade. Outra matéria que aborda a questão dos cotistas foi publicada pelo site Hypeness ${ }^{33}$. A reportagem também possui uma estrutura semelhante aos demais textos que compõem o corpus de análise. O gancho inicial da matéria é a apresentação de estatísticas sobre acesso ao ensino superior e a preocupação de dirigentes universitários com a saúde mental dos estudantes. Porém, a matéria destaca a "presença do racismo como um dos elementos decisivos na deterioração da saúde mental" 3 . No texto, a narrativa de confronto também está presente, mas se altera. Já não são estudantes que se colocam contra instituições de ensino, mas a sociedade contra o racismo. Uma estudante declara, "o que observamos desde a implantação da política de cotas é o acirramento dos conflitos. Inclusive no campo epistêmico e dos mais variados pontos de vista. É extremamente preocupante, quando observamos que tais práticas não vêm sendo combatidas, nem os casos tratados com severidade" ${ }^{3}$. Uma psicóloga também é ouvida, mas o enfoque de sua fala escolhido pela reportagem foge ao modelo médico tradicional, ao apontar nexos entre o sofrimento estudantil e desigualdades sistêmicas: "essas relações são marcadas por diversos sistemas de opressões como machismo, racismo, lgbttfobia e ou preconceito de classe. Todas são geradoras de sofrimento, que acaba sendo intensificado quando estudantes se deparam com dificuldades comuns na leitura e produção textual, porque a vivência dessa dificuldade somada à vivência do preconceito, pode levar ao entendimento de que aquele não é o seu lugar, conforme o mito da meritocracia"33. Finalmente, a matéria, ao elencar iniciativas para combater os problemas de saúde mental, cita os centros de apoio psicológico, mas destaca a atuação dos coletivos estudantis, que seriam capazes de enfrentar a questão e prevenir suicídios por meio da oferta de "união, apoio e organização"33. Por um lado, 
essas matérias mantêm relação direta com as narrativas baseadas na política da vítima. Elas privilegiam indivíduos concretos, visam o reconhecimento do sofrimento das vítimas e distribuem a responsabilidade pelo sofrimento, concebido como evitável. Por outro, ao romper com a lógica da medicalização, vinculam a política do sofrimento estudantil a outras formas de ação política, capazes de problematizar regimes de produção de desigualdades que encontram na universidade apenas mais um ponto de irradiação.

São poucas as matérias que abordam a questão do sofrimento psíquico dos estudantes utilizando parâmetros de referência externos à vida universitária. A ausência de horizontes que ultrapassam o ensino superior contribui para a construção de sentidos que tomam o sofrimento e o adoecimento psíquico na universidade como uma questão específica e isolada, que não se relaciona com dinâmicas e fenômenos mais amplos que ocorrem em outras áreas da sociedade brasileira. Predominantemente, não se articula, nos textos observados, a relação entre o mal-estar estudantil e o mal-estar da população em geral. De modo semelhante, são poucas as matérias que fazem referência à existência de debates sobre saúde mental no ensino superior em países estrangeiros. Algumas reportagens apontam que o mal-estar estudantil está relacionado às incertezas que marcam o futuro profissional. Mas, nenhuma matéria articula tal incerteza ao cenário atual de ampla precarização do trabalho e do aumento de desigualdades socioeconômicas estruturais.

Essa estratégia de construção discursiva do mal-estar estudantil revela suas inclinações políticas na medida em que sinaliza quais instituições sociais devem ser foco de transformação e onde devem ser investidos os esforços para ação coletiva. Ao retratar o sofrimento estudantil como um problema isolado, decorrente de falhas morais individuais, cujas vítimas devem receber acompanhamento médico, aponta-se para um horizonte de enfraquecimento da ação política por meio da patologização da condição do sofredor. O foco recai sobre a necessidade de tratar individualmente aqueles que sofrem. A universidade reproduz, portanto, mais uma lógica do neoliberalismo. $\operatorname{Han}^{13}$ observa que doenças psíquicas são uma das expressões mais contundentes das reconfigurações sociais promovidas pelo neoliberalismo. Segundo o autor, "no regime neoliberal de autoexploração, a agressão é dirigida contra nós mesmos. Ela não transforma os explorados em revolucionários, mas sim em depressivos" ${ }^{13}$. Entretanto, como observado em um pequeno conjunto de matérias, existem outras formas de codificar o sofrimento, que não envolvem apenas a assimilação do discurso da otimização pessoal ou o da medicalização.

\section{CONSIDERAÇÕES FINAIS}

Ao se perguntar qual tipo de narrativa sobre a cultura contemporânea pode responder ao fenômeno do crescimento de diagnósticos de doenças mentais, $\mathrm{Vaz}^{28}$ encontra três possíveis respostas. A primeira narrativa, baseada na crença do progresso científico, sustentaria que o saber médico se desenvolveu o bastante para identificar casos que outrora não seriam percebidos, mas que agora, graças ao avanço do conhecimento, podem ser identificados. Essa narrativa é assimilada por grande parte das matérias analisadas. Assim, o fenômeno do sofrimento psíquico e do adoecimento mental dos universitários é apresentado como uma espécie de descoberta ou revelação. O fenômeno sempre existiu, mas agora certas condições propiciaram sua visibilidade.

A segunda narrativa, de origem sociológica, sugere que não houve uma mudança de percepção sobre um fenômeno que sempre existiu, mas que certas configurações da sociedade contemporânea produziram, de fato, mais sofrimento. As doenças não seriam, portanto, objetos invariáveis à espera de serem identificados, mas resultantes de configurações sociais e econômicas específicas. Tipos de sofrimento surgem e desaparecem à medida que os valores que ordenam a sociedade se transformam. Essa narrativa encontra eco nas matérias que atrelam a questão do sofrimento estudantil na universidade às formas de exclusão e preconceito social. Os estudantes sofrem porque a universidade se transformou e agora abriga 
indivíduos que antes não pertenciam a ela. Assim, as dinâmicas de desigualdade que antes impediam a entrada de certos grupos na universidade e continuam a perpassar a sociedade agora se manifestam de variadas formas, gerando sofrimento psíquico nas vítimas de preconceito.

A terceira narrativa, de orientação foucaultiana, também correlacionaria a expansão das doenças mentais a mudanças sociais e econômicas, mas sua principal preocupação recairia em problematizar especificamente como certas configurações culturais da sociedade alteram o modo como pensamos e experimentamos o sofrimento. Ao contrário da segunda narrativa, não haveria tanto uma expansão do sofrimento ou das doenças mentais, mas uma transformação na maneira de definirmos o que é sofrer. Se a narrativa anterior alimenta uma denúncia contra a sociedade que faz sofrer, a narrativa de matriz foucaultiana questiona a própria percepção do sofrimento e o modo como tal percepção é capaz de reordenar experiências que o indivíduo tem de si mesmo e do mundo. Problematizar as noções contemporâneas sobre o sofrimento é um exercício crítico de importante potencial político, uma vez que envolve suspender as concepções predominantes para pensar outras formas de atribuição de sentidos possíveis ao sofrimento, num infinito esforço de buscar a liberdade de inventar outros mundos, outras percepções. Questionar as narrativas de sofrimento estudantil na universidade, portanto, não significa marginalizar a dor de quem sofre, mas criar possibilidades e estender um convite para que nossas experiências sejam pensadas e vividas de outras maneiras, fora dos padrões dominantes.

\section{REFERÊNCIAS}

1. V Pesquisa nacional de perfil socioeconômico e cultural dos(as) graduandos (as) das IFES: 2018 [Internet]. Brasília: ANDIFES, FONAPRACE, Universidade Federal de Uberlândia; 2019 [acesso em 2020 jul. 17]. Disponível em: https://bit.ly/3fIyMcM.

2. Perfil Socioeconômico e Cultural dos Estudantes de Graduação das Instituições Federais de Ensino Superior: 1997 [Internet]. Belo Horizonte: FONAPRACE; 1997 [acesso em 2020 jul. 23]. Disponível em: https://bit.ly/3jAVeH5.

3. II Perfil Socioeconômico e Cultural dos Estudantes de Graduação das Instituições Federais de Ensino Superior: 2004 [Internet]. Brasília: FONAPRACE; 2004 [acesso em 2020 jul. 23]. Disponível em: https:// bit.ly/2OR3jcE.

4. III Pesquisa nacional de perfil socioeconômico e cultural dos(as) graduandos (as) das IFES: 2011 [Internet]. Brasília: ANDIFES, FONAPRACE; 2011 [acesso em 2020 jul. 23]. Disponível em: https://bit. ly/2CZSouI.

5. IV Pesquisa nacional de perfil socioeconômico e cultural dos(as) graduandos (as) das IFES: 2016 [Internet]. Brasília: ANDIFES, FONAPRACE, Universidade Federal de Uberlândia; 2016 [acesso em 2020 jul. 23]. Disponível em: https://bit.ly/2ZVrbSR.

6. Mazetti H. As políticas do sofrimento na universidade e os debates online sobre saúde mental. XXVIII Encontro Anual da Compós; Porto Alegre: PUC-RS; 2019.

7. Foucault M. Arqueologia do saber. Rio de Janeiro: Forense Universitária; 1987.

8. Foucault M. A ordem do discurso. São Paulo: Editora Loyola; 1996.

9. Dunker C. Reinvenção da intimidade: políticas do sofrimento cotidiano. São Paulo: Ubu; 2017.

10. Ehrenberg A. La société du malaise. Paris: Odile Jacob; 2010.

11. Vaz P. Compaixão, moderna e atual. In: Freire Filho J, Coelho MGP, organizadores. Jornalismo, cultura e sociedade: visões do Brasil contemporâneo. Porto Alegre: Sulina; 2014. p. 73-96.

12. Illouz E. Cold intimacies: the making of emotional capitalism. Cambridge: Polity Press; 2007.

13. Han B. Psicopolítica: o neoliberalismo e as novas técnicas de poder. Belo Horizonte: Âyiné; 2018.

14. Cambricoli F, Toledo LF. Aumento de transtornos mentais entre jovens preocupa universidades. Estadão [Internet]. 2017 set. 16 [citado em 2020 jan. 28]. Disponível em: https://bit.ly/2CRTSXy. 
15. Cambricolli F, Toledo LF. Eu deixei de ter prazer em ir às aulas', diz aluna de Medicina. Estadão [Internet]. 2017 set. 16 [citado em 2020 jul. 17]:Saúde. Disponível em: https://bit.ly/3967omE.

16. Cambricolli F, Toledo LF. Nas federais, 3 estudantes em cada 10 já procuraram psicólogo. Estadão [Internet]. 2017 set. 16 [citado em 2020 jan. 28]:Saúde. Disponível em: https://bit.ly/398TdgQ.

17. Cambricolli F, Toledo LF. Alunos relatam encontrar dificuldade para obter auxílio psicológico. Estadão [Internet]. 2017 set. 16 [citado em 2020 jul. 17]:Saúde. Disponível em: https://bit.ly/32xRG2n.

18. Erbolato ML. Técnicas de codificação em jornalismo: redação, captação e edição no jornal diário. São Paulo: Ática; 1991.

19. Christofoletti R. Ética no jornalismo. São Paulo: Contexto; 2012.

20. Ramos JCL, Souza EA. Ouça sempre o outro lado: a pluralidade de fontes na perspectiva dos manuais de redação. Novos Olhares [Internet]. 2019 [citado em 2020 jul. 18];8(2):109-19. Disponível em: http:// www.revistas.usp.br/novosolhares/article/view/155227.

21. Boltanski L. Distant suffering: morality, media and politics. Cambridge: Cambridge University Press; 1999.

22. Vaz P, Rony G. Políticas do sofrimento e as narrativas midiáticas de catástrofes naturais. Rev FAMECOS [Internet]. 2011 jan.-abr. [citado em 2020 jul. 18];18(1):218-34. Disponível em: http:// revistaseletronicas.pucrs.br/ojs/index.php/revistafamecos/article/view/8808.

23. Moraes FT. Estudantes de mestrado e doutorado relatam suas dores na pós-graduação. Folha de S.Paulo [Internet]. 2017 dez. 18 [citado em 28 jan. 2020]:Ciência. Disponível em: https://bit.ly/3eEYhdW.

24. Antunes J. Maioria dos estudantes da UnB apresenta sintomas de problemas como a depressão. Jornal de Brasília [Internet]. 2018 jul. 23 [citado em 2020 jan. 28]. Disponível em: https://bit.ly/3eHQ4FM.

25. Moraes FT. Suicídio de doutorando da USP levanta questões sobre saúde mental na pós. Folha de S.Paulo [Internet]. 2017 jul. 10 [citado em 2020 jul. 23]:Saúde. Disponível em: https://www1.folha.uol. com.br/ciencia/2017/10/1930625-suicidio-de-doutorando-da-usp-levanta-questoes-sobre-saude-mentalna-pos.shtml.

26. Conrad P. The medicalization of Society: On the Transformation of Human Conditionsinto Treatable Disorders. Baltimore: The Johns Hopkins University Press; 2007.

27. Metzl J. Introduction: Why against health? In: Metzl J, Kirkland A, organizers. Against health: how health became the new morality. Nova York: NYU Press; 2010. p. 1-14.

28. Vaz P. Do normal ao Consumidor: conceito de doença e medicamento na contemporaneidade. Ágora: Estudos em Teoria Psicanalítica [internet]. 2015;18(1):51-68. Disponível em: http://www.scielo.br/scielo. php?script=sci arttext\&pid=S1516-14982015000100051.

29. Albuquerque A. Universidades criam programas para combater solidão universitária e depressão de estudantes. G1 Sorocaba e Jundaí [Internet]. 2018 set. 21 [citado em 2020 jan. 28]. Disponível em: https://glo.bo/3eB5A6k.

30. Meira MEM. Para uma crítica da medicalização na educação. Psicol Esc Educ [Internet]. 2012 [citado em 2020 jan. 28];16(1):135-42. Disponível em: http://www.scielo.br/scielo.php?pid=S1413$\underline{85572012000100014 \& \text { script=sci abstract\&tlng=pt. }}$.

31. Lemos FCS. A medicalização da educação e da resistência no presente: disciplina, biopolítica e segurança. Psicol Esc Educ [Internet]. 2014 [citato em 2020 jan. 28]18(3):485-92. Disponível em: http://www.scielo.br/scielo.php?pid=S1413-85572014000300485\&script=sci abstract\&tlng=pt.

32. Barbosa C. A faculdade não está pronta para lidar com a permanência dos alunos cotistas. CartaCapital [Internet]. 2019 nov. 20 [citado em 28 jan. 2020]. Disponível em: https://www.cartacapital.com.br/ educacao/a-faculdade-nao-esta-pronta-para-lidar-com-a-permanencia-dos-alunos-c/.

33. Vieira K. Saúde mental $x$ democratização do ensino: como a diversidade pode brecar casos de suicídio. Hypeness [Internet]. 2018 set. 10 [citado em 28 jan. 2020]. Disponível em: https://www.hypeness. com.br/2018/09/saude-mental-x-democratizacao-do-ensino-como-a-diversidade-pode-brecar-casos-desuicidio/. 